\title{
Relationship between High Performance Work System and Patient Safety: Study on Saudi Arabia Public Hospitals
}

\author{
Alotaibi Eqab Aiyadh ${ }^{1}$, Rushami Zien Yusoff ${ }^{2}$, Omar Zayyan AlSharqi ${ }^{3}$ \& Ebrahim Mohammed Al-Matari ${ }^{4}$ \\ ${ }^{1}$ Ministry of Health Saudi Arabia and School of Business Management (SBM), College of Business, University \\ Utara Malaysia, 06010 UUM, Kedah, Malaysia \\ ${ }^{2}$ School of Business Management (SBM), College of Business, University Utara Malaysia, 06010 UUM, Kedah, \\ Malaysia \\ ${ }^{3}$ Faculty of Economics and Aministration, King Abdulaziz University, Saudi Arabia \\ ${ }^{4}$ Faculty of Business and Economics, Ammran University, Yemen and Othman Yeop Abdullah Graduate School \\ of Business, University Utara Malaysia, Malaysia \\ Correspondence: Alotaibi Eqab Aiyadh, Ministry of Health Saudi Arabia and School of Business Management \\ (SBM), College of Business, University Utara Malaysia, 06010 UUM, Kedah, Malaysia. E-mail: \\ aldhiyabi08@yahoo.com
}

Received: October 21, 2014

Accepted: November 24, 2014

Online Published: December 20, 2014

doi:10.5539/ijbm.v10n1p115

URL: http://dx.doi.org/10.5539/ijbm.v10n1p115

\begin{abstract}
This paper investigated Relationship between High Performance work system and patient safety in Saudi Arabia Public Hospitals. Patient safety is a critical indicator of the quality of healthcare system, and reflects the degree to which performances comply with systems and guidelines which haven't negative impact on patient health. High performance work system which is designed to enhance employees' commitment and skills and ultimately improve organizational performance. The aim of this study is the analyzing of high performance work system and patient safety in Saudi Arabia hospitals. In order to achieve the study objective in the present study, a cross-sectional survey design using a self-administered questionnaire will be carried out. Questionnaires distributed to the nurses managers in Saudi Arabia Hospitals. A quantitative research design was adopted to collect data. Out of 254 questionnaires returned which are content to 202 questionnaires returned from 112 general hospitals and 52 from 33 specialist hospitals only 217 questionnaires used for analysis. The Partial Least Squares Structural Equation Modeling (PLS-SEM). The findings showed the relationship between High Performance work system and patient safety was positively supported.
\end{abstract}

Keywords: patient safety, high performance work system, health care

\section{Introduction}

Patient safety has become a significant topic among health professionals, policy makers, and the public owing to the emphasis on the reported and unreported healthcare errors that result in negative situations. Several initiatives and studies dedicated to patient safety have been conducted in the Western countries that are characterized by well-organized healthcare systems and effectively implemented quality assurance programs (Al Rifai, 2008). In contrast, developing countries lack the infrastructure required for the implementation and lack resources to tackle patient safety. On the basis of the report of the World Health Organization (WHO, 2004), deficiencies in healthcare systems in terms of infrastructure, lack of skilled personnel and other quality issues are still prevalent in the developing countries.

Patient safety is a critical indicator of the quality of healthcare system (Berntsen, 2004), and reflects the degree to which performance comply with systems and guidelines which haven't negative impact on patient health. Within health care systems, health professionals are increasingly required to incorporate patient safety principles and concepts into their everyday practice (World Health Organization, 2009). On the frontline of the health care professionals, nurses are placed ideally to ensure the safety and quality within health care because of their unique proximity to patients. Although there are some attempts to explore the links between nursing care and quality of outcomes, relatively little was conducted on the connection between nursing care and patient safety (Richardson \& Storr, 2010). Moreover, researchers have addressed recently that the great majority of nurses as well as 
physicians and administrators believe that nursing staff has the primary responsibility for assuring patient safety (Cook, et al., 2004). Reports from many countries highlighted that significant numbers of patients are harmed due to their health care, either resulting in permanent injury, increased length of stay in hospitals or even death (World Health Organization, 2009).

In this context, the Ministry of Health $(\mathrm{MOH})$ has tried a number of strategies in the past decades to improve the management of public hospitals, including direct operation by the $\mathrm{MOH}$, cooperation with other governments such Netherlands, Germany and Thailand, partial operation by health care companies, comprehensive operation by health care companies and the autonomous hospital system (Al-Ateeq, 2002). Considering the advantages and disadvantages of these approaches, the $\mathrm{MOH}$ has standardized an autonomous hospital system for 31 public hospitals in various regions (MOH, 2012). The autonomous hospital system for public hospitals was expected to raise the efficiency of their performance in both medical and managerial functions, achieve financial and administrative flexibility through adopting a direct budget strategy, apply quality insurance programs and simplify the contractual process with qualified health professionals (Al-Ateeq, 2002). In 2009, the MOH issued new regulations for self-operating public hospitals to ensure high level of management practices and to improve the quality of services provided (Al-Zahrani, 2009). It was suggested that giving more autonomy to hospitals would help the transition to full privatization of public hospitals in Saudi Arabia as it gives public hospitals more experience in the management of their budgets, health care quality and workforce (Almalki et al., 2011).

High performance work system (HPWS) which is also referred to (high performance workplaces, high commitment workplaces, high-involvement work systems and high performance practice) are systems which are designed to enhance employees' commitment and skills (Zacharatos et al., 2005) and ultimately improve organizational performance (Boxall \& Macky, 2007; Bartram et al., 2007; Datta, et al., 2005). There are many definitions of HPWS, however, the most common one is that the systems of managerial practices which increase the empowerment of employees and enhance the skills and incentives that enable and motivate them to take advantage of this greater empowerment (Macky \& Boxall, 2007).

High performance work systems (HPWS) are actually "human resource management practices" that can ensure better managerial outcome and also better employee experience of work (Harley, et al., 2007). HPWS can also be described as the systematic use of mutually reinforcing human resource management (HRM) practices which have an emphasis on selecting the 'right' employees, developing their skills, organizing work so that employees have the discretion to solve problems creatively, and the use of reward systems which motivate employees to work effectively in pursuit of organizational goals (Harley, et al., 2007).

Saudi Arabia has a unique position in the Islamic world, as it embraces the two holiest cities of Islam, Mecca and Medina. About two million pilgrims from all over the world perform the hajj annually, out of them about $69.8 \%$ come from foreign countries (Health Statistical Yearbook., 2009). Hosting such an event annually is a major challenge that requires a planned and organized effort across numerous agencies and departments to ensure adequate essential services, such as housing, transport, safety and health care (Jannadi et al., 2008). Health care services in the hajj season provide preventive and curative care for all pilgrims, irrespective of their nationality. The provision of emergency and curative services takes place through a network of health care facilities. For example, in 2009, there were 21 hospitals, of which 7 were seasonal, with a total of 3408 beds and 176 beds for emergency admissions. On average, each physician treated about 612 pilgrims, while each nurse treated about 372 (Health Statistical Yearbook, 2009).

High performance work systems are viewed as an expression of a shift in management paradigm. The traditional and highly hierarchy-oriented management approach is replaced with a more democratic system that encourages sharing of responsibility. Here, the "control mechanisms" are relaxed, "open communication" is encouraged, and "joint decision-making" with better employee participation is brought about. Thus the employees are allowed to be more creative and innovative (Kaiser, 2011). Employee participation in decision making is an important HPWP that can lead to motivation and team work (Naqvi \& Nadeem, 2011). A negative example in this context can be the use of "electronic monitoring and control" by the company. This has been found to cause higher turnover and this is explained by the fact that such monitoring and control actually "signal mistruct" (Batt, 2002).

Patient safety has become foremost critical issue in the last decade either in the developed countries or in the developing countries (Nygren et al., 2013). In To Err Is Human (Kohn et al., 2000), the Institute of Medicine (IOM) report emphasizes that patient safety is "the avoidance, prevention and amelioration of adverse outcomes or injuries stemming from the process of health care" (p. 57). Despite of the growing global concern about patient safety accompanied by the recent advances in medical technologies and several researches' conceptualization of patient safety, the reports and statistics about patient safety are scarce even in developed 
countries (Shojania, Duncan, McDonald, Wachter, \& Markowitz, 2001). The review of these scarce available statistics clearly points to critical level of patient safety worldwide, for example, the statistics published by the Committee on Quality of Health Care in America and Institute of Medicine (2000) revealed that the annual total deaths due to preventable medical errors in USA were estimated to exceed 44,000 patients. In light of this and other similar alarming statistics from other institutes (Jao \& Hier, 2010), it was ascertained that medical errors not only threaten the quality of healthcare and increase healthcare costs, but it also adds to the medical malpractice crisis (Studdert et al., 2005). The aim of this study is to obtain the relationship between high performance work system and patient safety in Saudi Arabia Hospitals.

\section{Materials and Method}

\subsection{Research Framework}

Figure 1 presents the overall representation of the theoretical framework that depicts the relationships between leadership, HPWS, organizational climate, effective reporting system and patient safety. Based on the fragmented empirical evidence, the current study suggests a coherent model investigating these relationships in a single model.

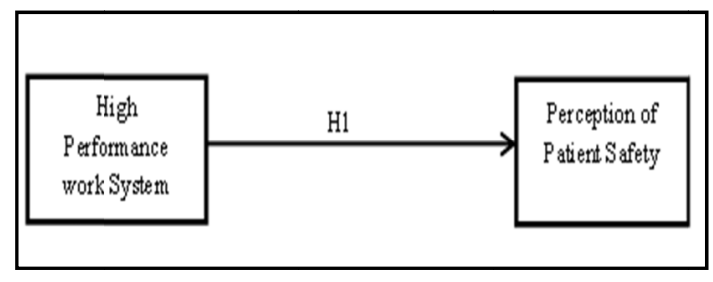

Figure 1. Research framework

\subsection{Hypotheses Development}

\subsubsection{Relationship between High Performance Work System and Patient Safety}

Previous studies showed a positive relationship between HPWS and better outcome (Takeuchi et al., 2007). West et al. (2006) aimed to find out the relationship between the high performance policies and practices on health care outcome represented by standardized patient mortality rates in a sample of 52 hospitals in England. He found that the greater the use of a comprehensive set of high performance policies and practices, the better the outcome in terms of patient mortality. However, recent researches advocated that the establishment of a safer health care system necessitates more studies to be conducted to identify system factors that contribute to the occurrence of medical errors, as these are expected to provide foundations for process and system improvements to reduce those errors (Al-Saleh \& Ramadan, 2012). Moreover, several authors (Takeuchi et al., 2007) highlighted that existing studies do not providing adequate evidence on the relationship between HPWS, firm practice and proposed outcome. Takeuchi et al. (2009) later expressed that the relationship between HPWS and outcome is still obscure as there is paucity in research works providing evidence for this relationship and the mechanisms through which this relationship is established. Therefore, the current research hypothesizes the following:

Hypothesis 1: High performance work system (HPWS) has a significant effect on Perception of patient safety.

\section{Results}

\subsection{Descriptive Statistics Analysis}

To get a summary of the data, a descriptive analysis on all constructs was run. Table 1 shows the result. All constructs had mean values ranging from 2.691 to 3.983 and standard deviation from 0.835 to 1.378 . 
Table 1. Descriptive statistics of the constructs $(n=217)$

\begin{tabular}{lllll}
\hline Constructs & Minimum & Maximum & Mean & Std. deviation \\
\hline Recruitment/hiring & 1 & 5 & 3.656 & 3.983 \\
Training & 1 & 5 & 3.922 & 1.155 \\
Performance appraisal & 1 & 5 & .295 \\
Job security & 1 & 5 & 3.691 \\
Participation & 1 & 5 & 3.163 \\
perception of patient safety & 1 & 5 & 3.747 \\
\hline
\end{tabular}

\subsection{Test of Normality}

According to Hair et al. (2006) the values of skewness outside the range of +1 to -1 are substantially skewed distribution. However, Kline (1998) suggested the cut off between +3 to -3 will be acceptable. Based on these criteria suggested by many researchers, the skewness values were within the acceptable range suggested by Kline (1998) (+3 to -3), however, not acceptable values according to Hair et al. (2006) (+1 to -1). Similarly, the values of kurtusis are suggested by Coakes and Steed (2003) to range from +3 to -3 which are acceptable based on the below Table 2 .

Based on discussion above, the results show that some of values in skewness deviate from being normally distributed. Therefore, to be able to handle nor-normal and skewed data to test the hypothesized relationships, this study employed PLS Structural Equation Modeling that is the distribution free statistical modeling technique (Chin, 1998).

Table 2. Results of Skweness and Kurtusis for normality test

\begin{tabular}{|c|c|c|c|c|}
\hline \multirow{2}{*}{ Constructs } & \multicolumn{2}{|l|}{ Skewness } & \multicolumn{2}{|l|}{ Kurtosis } \\
\hline & Statistic & Std. Error & Statistic & Std. Error \\
\hline Recruitment/Hiring & -.922 & .165 & -.530 & .329 \\
\hline Training & -1.329 & .165 & .884 & .329 \\
\hline Performance Appraisal & -.704 & .165 & -.492 & .329 \\
\hline Job Security & .244 & .165 & -1.319 & .329 \\
\hline Participation & -.990 & .165 & .526 & .329 \\
\hline Perception of Patient safety & -1.758 & .165 & 3.766 & .329 \\
\hline
\end{tabular}

\subsection{Construct Validity}

Construct validity refers to the degree to which the items generated to measure a construct can appropriately measure the concept they were designed to measure (Hair et al., 2010). More specifically, all the items designed to measure a construct should load higher on their respective construct than their loadings on other constructs. This was ensured by a comprehensive review of the literature to generate the items that already have been established and tested in previous studies.

Based on factor analysis, items were correctly assigned to their constructs. Construct validity was the item loadings significantly loaded on their respective constructs (Chow \& Chan, 2008). Table 3 shows the result. 
Table 3. Significance level of factor loadings

\begin{tabular}{|c|c|c|c|c|c|}
\hline Construct & Items & Loadings & Std. error & $\mathbf{t}$ & $\mathbf{p}$ \\
\hline \multirow[t]{2}{*}{ Job Security } & emp1 & 0.965 & 0.004 & 217.759 & 0.000 \\
\hline & emp2 & 0.964 & 0.005 & 211.896 & 0.000 \\
\hline \multirow[t]{3}{*}{ Participation } & part1 & 0.845 & 0.021 & 39.799 & 0.000 \\
\hline & part2 & 0.884 & 0.020 & 45.083 & 0.000 \\
\hline & part3 & 0.871 & 0.015 & 59.951 & 0.000 \\
\hline \multirow[t]{3}{*}{ Appraisal } & perf1 & 0.851 & 0.011 & 76.677 & 0.000 \\
\hline & perf2 & 0.799 & 0.033 & 23.925 & 0.000 \\
\hline & perf3 & 0.876 & 0.019 & 45.029 & 0.000 \\
\hline \multirow[t]{3}{*}{ Recruitment/Hiring } & recruit1 & 0.926 & 0.013 & 72.424 & 0.000 \\
\hline & recruit2 & 0.900 & 0.018 & 50.966 & 0.000 \\
\hline & recruit3 & 0.896 & 0.015 & 57.946 & 0.000 \\
\hline \multirow[t]{3}{*}{ Training } & train1 & 0.962 & 0.006 & 151.569 & 0.000 \\
\hline & train 2 & 0.952 & 0.010 & 90.982 & 0.000 \\
\hline & train3 & 0.959 & 0.007 & 140.408 & 0.000 \\
\hline \multirow[t]{3}{*}{ Perception of Patient safety } & saft1 & 0.862 & 0.044 & 19.519 & 0.000 \\
\hline & saft2 & 0.930 & 0.010 & 89.004 & 0.000 \\
\hline & saft3 & 0.637 & 0.055 & 11.553 & 0.000 \\
\hline
\end{tabular}

\subsection{Convergent Validity of the Measurements}

Table 4 shows that the composite reliability values ranged from 0.860 to 0.964 . These values exceeded the recommended value of 0.7 (Fornell \& Larcker, 1981; Hair et al., 2010). The average variances extracted (AVE) values ranged between 0.710 and 0.931 , indicating a good level of construct validity of the measures used (Barclay et al., 1995). These results confirm the convergent validity of the outer model.

Table 4. Convergent validity analysis

\begin{tabular}{|c|c|c|c|c|c|}
\hline Construct & Items & Loadings & Cronbach's alpha & $\mathbf{C R}^{\mathrm{a}}$ & $\mathbf{A V E} \mathbf{E}^{\mathrm{b}}$ \\
\hline \multirow[t]{2}{*}{ Job Security } & emp1 & 0.965 & 0.926 & 0.964 & 0.931 \\
\hline & emp2 & 0.964 & & & \\
\hline \multirow[t]{3}{*}{ Participation } & part1 & 0.845 & 0.835 & 0.901 & 0.751 \\
\hline & part2 & 0.884 & & & \\
\hline & part3 & 0.871 & & & \\
\hline \multirow[t]{3}{*}{ Appraisal } & perf1 & 0.851 & 0.799 & 0.880 & 0.710 \\
\hline & perf2 & 0.799 & & & \\
\hline & perf3 & 0.876 & & & \\
\hline \multirow[t]{3}{*}{ Recruitment/Hiring } & recruit1 & 0.926 & 0.893 & 0.933 & 0.824 \\
\hline & recruit2 & 0.900 & & & \\
\hline & recruit3 & 0.896 & & & \\
\hline \multirow[t]{3}{*}{ Training } & train1 & 0.962 & 0.955 & 0.971 & 0.917 \\
\hline & train2 & 0.952 & & & \\
\hline & train3 & 0.959 & & & \\
\hline \multirow[t]{3}{*}{ Perception of Patient safety } & saft1 & 0.862 & 0.764 & 0.857 & 0.672 \\
\hline & saft2 & 0.930 & & & \\
\hline & saft3 & 0.637 & & & \\
\hline
\end{tabular}

Note. ${ }^{a}$ Composite Reliability $(\mathrm{CR})=(\Sigma \text { factor loading })^{2} /\left\{(\Sigma \text { factor loading })^{2}\right)+\Sigma$ (variance of error $\left.)\right\}$;

${ }^{\mathrm{b}}$ Average Variance Extracted $(\mathrm{AVE})=\Sigma(\text { factor loading })^{2} /(\Sigma \text { (factor loading })^{2}+\Sigma$ (variance of error $\left.)\right\}$.

\subsection{Discriminant Validity of the Measures}

The discriminant validity of the measures was confirmed by employing the method of Fornell and Larcker (1981). As illustrated in Table 5, the square root of average variance extracted (AVE) for all the constructs were placed at the diagonal elements of the correlation matrix. As the diagonal elements were higher than the other 
elements of the row and column in which they were located, this confirms the discriminant validity of the outer model. In sum, having established the construct validity of the outer model, it is assumed that the obtained results pertaining to the hypotheses testing should be valid and reliable.

Table 5. Discriminant validity analysis

\begin{tabular}{lllllll}
\hline Constructs & $\mathbf{1}$ & $\mathbf{2}$ & $\mathbf{3}$ & $\mathbf{4}$ & $\mathbf{5}$ & $\mathbf{6}$ \\
\hline 1) Appraisal & $\mathbf{0 . 8 4 3}$ & & & & & \\
2) Job Security & 0.101 & $\mathbf{0 . 9 6 5}$ & & & & \\
3) Perception of Patient safety & 0.289 & 0.418 & $\mathbf{0 . 8 1 9}$ & & & \\
4) Participation & 0.575 & 0.620 & 0.370 & $\mathbf{0 . 8 6 7}$ & & \\
5) Recruitment/Hiring & 0.367 & 0.500 & 0.327 & 0.440 & $\mathbf{0 . 9 0 8}$ & \\
6) Training & 0.720 & 0.365 & 0.631 & 0.565 & 0.454 & $\mathbf{0 . 9 5 8}$ \\
\hline
\end{tabular}

\subsection{Assessing the Inner Model and Hypotheses Testing Procedures}

After the goodness of the outer model had been ascertained, the next step was to test the hypothesized relationships among the constructs. Using the Smart PLS 2.0, the hypothesized model was tested by running the PLS algorithm.

To be able to conclude whether the path coefficients were statistically significant or not, this study employed the bootstrapping techniques embedded with the Smart PLS 2.0. To run bootstrapping of this model, the researcher used 500 samples with number of cases equal to the observations out of 217 cases. More specifically, the T values accompanying each path coefficient was generated using the bootstrapping technique and subsequently the $\mathrm{p}$ values were generated, as reported in Table 6 .

Result showed that the influence of high performance work system on Perception of patient safety was positive and significant $(\beta=0.533, \mathrm{t}=10.590, \mathrm{p}<0.1)$, indicating the higher high performance work system leads to the high level of patient safety.

Table 6. Results of the inner structural model

\begin{tabular}{|c|c|c|c|c|c|c|}
\hline No & Hypotheses & Path coefficient & Std. error & $\mathbf{T}$ & $\mathbf{p}$ & Decision \\
\hline $\mathrm{H}_{1}$ & $\begin{array}{l}\text { High performance work system (HPWS) has a } \\
\text { significant effect on Perception of patient safety }\end{array}$ & $0.533 * * *$ & 0.050 & $\begin{array}{l}10.59 \\
0\end{array}$ & $\begin{array}{l}0.00 \\
0\end{array}$ & $\begin{array}{l}\text { Supporte } \\
\text { d }\end{array}$ \\
\hline
\end{tabular}

Note. ${ }^{*} \mathrm{p}<0.1 ; * * \mathrm{p}<0.05 ; * * * \mathrm{p}<0.01$.

\section{Discussions}

\subsection{High Performance Work System and Overall Perception of Patient Safety}

Result showed a positive and significant direct effect of high performance work system on the perceived patient safety which at the 0.01 level of significance $(\beta=0.533, \mathrm{t}=10.590, \mathrm{p}<0.10)$, This result is in line with a study conducted by West, Guthrie, Dawson, Borrill, and Carter (2006) in 52 hospitals in England. They found that the adoption of a complementary set of high performance human resource management policies and practices was significantly related to patient mortality. In examining the effect of HPWS on improved patient outcomes in Australian hospitals, Bonias, Bartram, Leggat, and Stanton (2010) found positive and significant result. They also observed that HPWS was not directly related to perception of employees, but was mediated by components of psychological empowerment of autonomy and competence. Although extensive work has been done on the relationship between HPWS and performance outcome in manufacturing organizations, the result of this study seems to validate further such finding.

The direct effect of HPWS on patient safety confirms Donabedian theory which is concerned about the quality of outcome and its relationship with the structure and processes (Donabedian, 1980). Several scholars indicated that human resource policies and practices are likely to impact patient care quality by influencing both technical and interpersonal aspects (Flood, 1994; Laschinger, Shamian, \& Thomson, 2001). In this respect, the finding implies the importance of interpersonal features within the health institution including the relationship between health care professionals and their patients in addition to their relationship with others within the organization. The 
finding of the present study contributes to the existing knowledge as the above studies were conducted in a different context. But regardless of the contexts, it seems that the effect of HPWS on organizational performance (such as patient safety as one of the indicators of performance) holds true.

\section{Conclusions}

In conclusion, patient safety in the hospitals expressed either in terms of number of patients acquired adverse events or costs of treatment and compensations are considered as real problems in Saudi Arabia as is the case in many countries worldwide. It is expected that patient safety is interrelated with a complicated web of factors including HPWS, leadership and organization climate. Despite its importance, the full scope of these relationships with patient safety is not well studied.

The motivation for the study arose from the critical situation of patient safety in the hospitals in Saudi Arabia. In addition, this study offers a unique opportunity to consider specific high performance work system, in the context of healthcare in Saudi Arabia. Furthermore, high performance work system, and patient safety in Saudi Arabia hospitals would provide meaningful data to administrators and staff members in different ways. First, this study helps hospital directors to better realize their influence on patient safety. This study further contributes to an understanding how high performance work system influence on patient safety in the hospital. Ultimately, from theoretical perspective, this study contributes to the previous knowledge in a number of ways. First, this study contributes to fortify the model describing different hospital organizational factors related to patient safety. Second, this study also adds to the body of literature by focusing on multiple items describing the organizational climate as a mediating factor for patient safety.

To conclude, it is clear that any health care organization needs to develop an organizational climate that can improve patient safety. There is enough research evidence to support this. Yet, what specifically constitutes the organizational climate remain a matter of definition and context, though it has become clear that the human element and collective perception could be the two major factors in that. The role of leadership and HPWS in improving patient safety has also been established, though it cannot be claimed that enough data has been generated to prove this connection beyond doubt. Most often, organizational climate is viewed as an outcome of leadership and HPWS and hence the attempt of this particular study to see them as mediated by organizational climate could face some degree of difficulties, regarding research design and methodology. Yet, this research angle is the natural outgrowth of what has already been established. Once the components of HPWS are well-established and the role of leadership in the whole process is acknowledged, the next step naturally has to be an investigation into the reciprocal relationships involved, that is, how this newly formed organizational climate mediates leadership and HPWS towards patient safety. It is also important to identify and weigh the intermediate links that enables organizational climate to mediate leadership and HPWS towards better patient safety.

\section{References}

Al Rifai, F. (2008). Nurse Excutives' Perception of Barriers and Facilitator.

Al-Ateeq, F. A. (2002). Experience of Saudi Arabia in operation of public hospitals: the transition from companies' operating system to self-operating system. Paper presented at the Conference on Recent Trends in the Management of Private and Public Hospitals in the Arab World, 12-14 March 2002. Cairo, Arab Administrative Development Organisation.

Almalki, M., Fitzgerald, G., \& Clark, M. (2011). Health care system in Saudi Arabia: an overview. East Mediterr. Health J., 17(10), 784-793.

Al-Saleh, K. S., \& Ramadan, M. Z. (2012). Studying Medical Errors among Hospital-Staff at Saudi Health Providers. Journal of Materials Science and Engineering, 2(1), 43-54.

Al-Zahrani, S. (2009). Requiring employees of self-operating public hospitals to work for six days per week instead of five. Al-Madinah Daily.

Batt, R. (2002). Managing customer services: Human resource practices, quit rates, and sales growth. Academy of Management Journal, 45(3), 587-597. http://dx.doi.org/10.2307/3069383

Berntsen, K. J. (2004). Valuable lessons in patient safety: reporting near misses in healthcare. J. Nurs. Care Qual., 19(3), 177-179. http://dx.doi.org/10.1097/00001786-200407000-00001

Boxall, P., \& Macky, K. (2009). Research and theory on high-performance work systems: progressing the high-involvement stream. Human Resource Management Journal, 19, 3-23. http://dx.doi.org/10.1111/j.1748-8583.2008.00082.x

Chin, W. W. (1998). The partial least squares approach for structural equation modeling. 
Chow, W. S., \& Chan, L. S. (2008). Social network, social trust and shared goals in organizational knowledge sharing. Information \& Management, 45(7), 458-465. http://dx.doi.org/10.1016/j.im.2008.06.007

Coakes, S. J., \& Steed, L. (2003). SPSS: Analysis without anguish. John Wiley \& Sons, Inc.

Cook, A. F., Hoas, H., Guttmannova, K., \& Joyner, J. C. (2004). An error by any other name. AJN The American Journal of Nursing, 104(6), 32-43. http://dx.doi.org/10.1097/00000446-200406000-00025

Datta, D. K., Guthrie, J. P., \& Wright, P. M. (2005). Human resource management and labor productivity: does industry matter? Academy of Management Journal, 48, 135-145. http://dx.doi.org/10.5465/AMJ.2005.15993158

Donabedian, A. (1982). Explorations in quality assessment and monitoring: the definition of quality and approaches to its assessment. Vol. II. The criteria and standards of quality. Ann Arbor: Health Administration Press.

Flood, A. B. (1994). The impact of organizational and managerial factors on the quality of care in health care organizations. Medical Care Research and Review, 51(4), 381-428. http://dx.doi.org/10.1177/107755879405100402

Fornell, C., \& Larcker, D. F. (1981). Evaluating structural equation models with unobservable variables and measurement error. Journal of Marketing Research, 39-50. http://dx.doi.org/10.2307/3151312

Hair, J. F., Anderson, R. E., Tatham, R. L., \& Black, W. C. (2010). Multivariate Data Analysis (7th ed.). Prentice Hall: USA.

Hair, J. F., Black, W. C., Babin, B. J., \& Anderson, R. E. (2010). Multivariate data analysis: a global perspective. Pearson Education.

Hair, J. F., Money, A. H., Samouel, P., \& Page, M. (2007). Research methods for business. USA, West Sussex: John Wiley \& Sons.

Hair, J. F., Sarstedt, M., Ringle, C. M., \& Mena, J. A. (2012). An Assessment of the Use of Partial Least Squares Structural Equation Modeling in Marketing Research. Journal of the Academy of Marketing Science, 40(3), 414-433. http://dx.doi.org/10.1007/s11747-011-0261-6

Hair, J. F., Tatham, R. L., Anderson, R. E., \& Black, W. (2006). Multivariate data analysis (6th ed.). Pearson Prentice Hall Upper Saddle River, NJ.

Harley, B., Allen, B. C., \& Sargent, L. D. (2007). High performance work systems and employee experience of work in the service sector: The case of aged care. British Journal of Industrial Relations, 45(3), 607-633. http://dx.doi.org/10.1111/j.1467-8543.2007.00630.x

Health Statistical Yearbook. (2009). Statistics Department, Ministry of Health (Saudi Arabia).

Jannadi, B., Alshammari, H., Khan, A., \& Hussain, R. (2008). Current Structure and Future Challenges for the Healthcare System in Saudi Arabia. Asia Pacific Journal of Health Management, 3(1), 43-50.

Jao, C. S., \& Hier, D. B. (2010). Clinical Decision Support Systems: An Effective Pathway to Reduce Medical Errors and Improve Patient Safety. Future, 4(4).

Kaiser, S. (2011). Strategic management of professional service firms. Berlin. http://dx.doi.org/10.1007/978-3-642-16063-9

Kline, R. B. (1998). Principles and practice of structural equation modeling. Guilford, New York.

Kohn, L. T., Corrigan, J. M., \& Donaldson, M. S. (2000). To err is human: building a safer health system. Washington, DC: National Academy Press.

Laschinger, H. K. S., Shamian, J., \& Thomson, D. (2001). Impact of magnet hospital characteristics on nurses' perceptions of trust, burnout quality of care, and work satisfaction. Nursing Economics, 19(5), 209-219.

Macky, K., \& Boxall, P. (2007). The relationship between G_shigh-performance work practices and employee attitudes: an investigation of additive and interaction effects. The International Journal of Human Resource Management, 18(4), 537-567. http://dx.doi.org/10.1080/09585190601178745

Naqvi, S., \& Nadeem, S. (2011). Impact of high performance work practices system on motivation. Interdisciplinary Journal of Contemporary Research in Business, 3(8), 197-210.

Nygren, M., Roback, K., Ohrn, A., Rutberg, H., Rahmqvist, M., \& Nilsen, P. (2013). Factors influencing patient safety in Sweden: perceptions of patient safety officers in the county councils. BMC health Services 
Research, 13(1), 52. http://dx.doi.org/10.1186/1472-6963-13-52

Richardson, A., \& Storr, J. (2010). Patient safety: a literature [corrected] review on the impact of nursing empowerment, leadership and collaboration. Int Nurs Rev., 57(1), 12-21. http://dx.doi.org/10.1111/j.1466-7657.2009.00757.x

Shojania, K. G., Duncan, B. W., McDonald, K. M., Wachter, R. M., \& Markowitz, A. J. (2001). Making health care safer: a critical analysis of patient safety practices Agency for Healthcare Research and Quality Rockville, MD.Springer.

Studdert, D. M., Mello, M. M., Sage, W. M., DesRoches, C. M., Peugh, J., \& Zapert, K. (2005). Defensive medicine among high-risk specialist physicians in a volatile malpractice environment. JAMA: The journal of the American Medical Association, 293(21), 2609-2617. http://dx.doi.org/10.1001/jama.293.21.2609

Takeuchi, R., Chen, G., \& Lepak, D. P. (2009). Through The Looking Glass of A Social System: Cross-Level Effects Of High Performance Work Systems on Employees' Attitudes. Personnel Psychology, 62(1), 1-29. http://dx.doi.org/10.1111/j.1744-6570.2008.01127.x

Takeuchi, R., Lepak, D. P., Wang, H., \& Takeuchi, K. (2007). An empirical examination of the mechanisms mediating between high-performance work systems and the performance of Japanese organizations. Journal of Applied Psychology, 92(4), 1069-1082. http://dx.doi.org/10.1037/0021-9010.92.4.1069

World Health Organization. (2004). Global priorities for patient safety research. WHO. Ref Type: Generic.

World Health Organization. (2009). WHO Patient Safety Curriculum Guide for Medical Schools. WHO/IER/PSP/2009.3S.

World Health Organization. (2012). Patient safety. Retrieved from http://www.who.int/patientsafety/research/en/

Zacharatos, A., Barling, J., \& Iverson, R. D. (2005). High-performance work systems and occupational safety. Journal of Applied Psychology, 90(1), 77. http://dx.doi.org/10.1037/0021-9010.90.1.77

\section{Copyrights}

Copyright for this article is retained by the author(s), with first publication rights granted to the journal.

This is an open-access article distributed under the terms and conditions of the Creative Commons Attribution license (http://creativecommons.org/licenses/by/3.0/). 